\title{
Environment Behavior and Fate of a Novel Pyrimidynyloxybenzoic Herbicide ZJ0273 in Aerobic Soil
}

\author{
Haiyan Wang, Yanfei Zhang, Man Yu, Juying Li, and Qingfu Ye \\ Zhejiang University, Institute of Nuclear Agricultural Sciences, \\ Hangzhou, 310029 \\ China
}

\section{Introduction}

Herbicides are universally used in crop production all over the world. Although herbicides are developed to be biologically active to weeds, their residues are frequently found in plants, soils, and surface and underground waters, where they may bring about a risk concern for human health, ecosystems, or the productivity of subsequent crops (Walker et al., 1997; Vithala \& White, 1996).

ZJ0273, propyl 4-(2-(4,6-dimethoxypyrimidin-2-yloxy)benzylamino) benzoate (shown in Fig. 1), is a new broad-spectrum herbicide (Lu et al., 2004; Yang et al., 2008). It is marketed under the trade names of Youli (EC) and Youli II (SC) in China, and both products were registered for use in oilseed rape in 2003. In recent years, the herbicide has been rapidly adopted for use in China with the cumulative application area reaching 666,667 hectares in 2009. Applications of the herbicide at the dosage of $40-60 \mathrm{~g}$ a.i. ha- ${ }^{-1}$ are commonly used to achieve effective control (80-90\%) in rape fields against pre- and post-emergence weeds, including equal alopecurus (Alopecurus aequalis Sobol.), crickweed (Malachium aquaticum L.), chickweed (Stellaria media L.), redroot amaranth (Amaranthus retroflexus L.), japanese alopecurus (Alopecurus japonicus Steud.), annual bluegrass (Poa annua L.), common polypogon (Polypogon fugax Nees ex Steud.), and spinefruit buttercup (Ranunculus muricatus L.) (Tang et al., 2005). ZJ0273 greatly inhibits acetolactate synthase (ALS) in vivo and it has little inhibitory effect on ALS in vitro, which differs from the typical commercial ALS inhibitors, such as sulfonylurea and pyrimidine salicylic acid herbicides.

Study on environmental behavior and fate for new agrochemicals in soil is an indispensable requirement for safe use of pesticides on food crops (Langenbach et al., 2000, 2001; Fent et al., 2003; Mordaunt et al., 2005). A series of issues, such as extractable residues, bound residue formation and mineralization of herbicides, as well as persistence time of parent compound, are of the most important concern. Many studies showed that soil-bound residues of herbicides, such as sulfonylurea herbicides, may cause damage to rotation or substitution crops (Moyer et al., 1990; Ye et al., 2003, 2004). In Europe, the Uniform Principles (CEC, 1997) state that in laboratory tests, if non-extractable soil residues are formed at $>70 \%$ of the initial dose after 100 days with mineralization to $\mathrm{CO}_{2}$ at $<5 \%$, there 
will be no authorization unless it is demonstrated that no accumulation of residues occurs in soil under field conditions (Craven, 2000; Craven and Hoy, 2005). In addition, it is important to understand if mineralization will detoxify agrochemicals with polyaromatic rings. However, up to now, relative information on ZJ0273 is still not well documented.
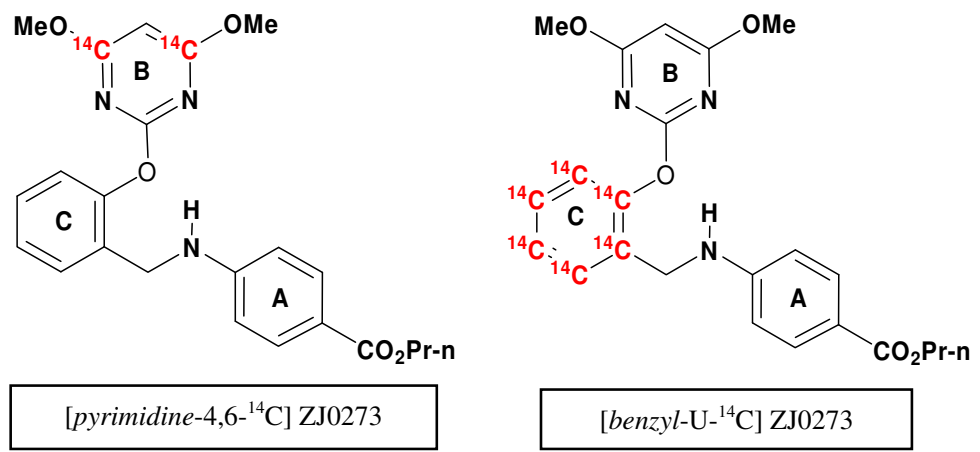

Fig. 1. Structures of radiotracers, ZJ0273 with asterisks marking the position of ${ }^{14} \mathrm{C}$.

Therefore, from the above, the aim of the present study, by using multi-14C-labeled propyl 4(2-(4,6-dimethoxypyrimidin-2-yloxy)benzylamino)benzoate, was to investigate environmental behavior and fate of the herbicide, characterize the fate processes, persistence, degradation pathways, bound residues formation, mineralization of ZJ0273, as well as plant availability and phytotoxicity of bound residues of ZJ0273 in wellcharacterized soils under aerobic conditions.

\section{Materials and methods}

\subsection{Chemicals}

Propyl 4-(2-(4,6-dimethoxy[4,6-14C]pyrimidin-2-yloxy)benzylamino)benzoate ([pyrimidine4,6-14C] ZJ0273; radiochemical purity $99.4 \%$; chemical purity $98.1 \%$; specific activity $3.77 \times$ $\left.10^{7} \mathrm{~Bq} / \mathrm{mmol}\right)$ and propyl 4-(2-(4,6-dimethoxypyrimidin-2-yloxy)[phenyl-U$\left.{ }^{14} \mathrm{C}\right]$ benzylamino)benzoate ([benzyl-U-14C] ZJ0273; radiochemical purity $98.9 \%$; chemical purity $98.1 \%$; specific activity $3.74 \times 10^{7} \mathrm{~Bq} / \mathrm{mmol}$ ), were synthesized according to the methods of Yang et al. (2008 \& 2009). The chemical purity was analyzed by high performance liquid chromatography (HPLC), and the radiochemical purity was determined by HPLC-liquid scintillation counting (LSC), and thin layer chromatography-isotope imaging analysis (TLC-IIA) (Yang et al., 2006 \& 2009).

\subsection{Soils}

Three different agricultural soils were used in the incubation experiment. The soils included a Red clayey soil $\left(\mathrm{S}_{1}\right)$, a Fluvio-marine yellow loamy soil $\left(\mathrm{S}_{2}\right)$ and a Coastal saline soil $\left(\mathrm{S}_{3}\right)$. The soil samples were taken from the surface layer $(0-15 \mathrm{~cm})$ in fields from different quarters of Zhejiang Province, China. The bulk soil samples were air dried, mixed, and passed through a 1-mm sieve before use. Some basic physicochemical characteristics of the soils were determined using standard methods (Nelson and Sommers, 1982; Gee and Bauder, 1986) and are given in Table 1. 


\subsection{Incubation experiments}

To characterize the fate processes of the herbicide ZJ0273 in aerobic soils, two multi-position ${ }_{14} \mathrm{C}$ labelings, [pyrimidine-4,6-14C] ZJ0273 and [benzyl-U-14C] ZJ0273 were employed in this study. Test vessels for the degradation study were 500-mL glass flasks. For each soil, a test system of three replicates was used. Prior to the application of [pyrimidine-4,6-14C] ZJ0273, $3 \times 300 \mathrm{~g}$ of soil (dry weight equivalent) was weighed for each soil and placed in sealed polypropylene bags, and the soil moisture content was adjusted to about $30 \%$ of the field water holding capacity by addition of distilled water. The test soils were then pre-incubated at $25 \pm 1{ }^{\circ} \mathrm{C}$ for $10 \mathrm{~d}$ to allow the microorganisms to acclimatize. After the initial acclimation, $15.0 \mathrm{mg}$ of [pyrimidine-4,6-14C] ZJ0273 $\left(3.77 \times 10^{7} \mathrm{~Bq} / \mathrm{mmol}\right)$ and $15.0 \mathrm{mg}$ of non-labeled analogue were dissolved in methanol, and $5.0 \mathrm{~mL}\left(1.340 \times 10^{5} \mathrm{~Bq}\right)$ was added to each soil sample. After the applied herbicide was thoroughly mixed, the treated soil samples were left in a fume hood to allow the evaporation of methanol and then transferred into incubation vessels. The water content of the spiked soil samples was adjusted to $60 \%$ of the water holding capacity by adding distilled water. Each incubation flask was connected to a series of air-tight test tubes, which allowed for the scrubbing of $\mathrm{CO}_{2}$ from the inlet air (with $5.0 \mathrm{M}$ $\mathrm{NaOH}$, two traps) and for maintaining constant soil moisture, and entrapment of volatiles (with $1.0 \mathrm{M} \mathrm{H}_{2} \mathrm{SO}_{4} /$ glycol, $5 / 10 \mathrm{v} / \mathrm{v}$, one trap) and ${ }^{14} \mathrm{CO}_{2}$ (with $10 \mathrm{~mL}$ of $0.5 \mathrm{M} \mathrm{NaOH}$, two traps) (Fig. 2; EPA, 2002). During incubation, a slow and continuous air flow was maintained in all systems at $25 \pm 2{ }^{\circ} \mathrm{C}$. At different time intervals $(5,10,20,30,45,60,75,90$ and $100 \mathrm{~d}$ after treatment), the traps and a subsample of the treated soils (10.0 g, air-dried weight equivalent) were removed to determine the radioactivity associated with extractable, non-extractable residue, and ${ }^{14} \mathrm{CO}_{2}$, as well as the fraction of [pyrimidine-4,6-14C] ZJ0273 remaining in the parent molecule form. The treatment and sampling for [benzyl-U-14C] ZJ0273 followed the same procedures as given above for [pyrimidine-4,6-14C] ZJ0273, except that $1.326 \times 10^{5} \mathrm{~Bq}$ of radioactivity was amended in each $300 \mathrm{~g}$ soil sample.

\begin{tabular}{|c|c|c|c|}
\hline \multirow{2}{*}{ Property } & \multicolumn{3}{|c|}{ Soil type } \\
\cline { 2 - 4 } & $\begin{array}{c}\mathrm{S}_{1} \\
\text { Red clayey soil }\end{array}$ & $\begin{array}{c}\mathrm{S}_{2} \\
\text { Fluvio-marine yellow loamy soil }\end{array}$ & $\begin{array}{c}\mathrm{S}_{3} \\
\text { Coastal saline soil }\end{array}$ \\
\hline $\mathrm{pH}\left(\mathrm{H}_{2} \mathrm{O}\right)$ & 4.20 & 7.02 & 8.84 \\
\hline $\mathrm{OM}^{\mathrm{a}}\left(\mathrm{g} \mathrm{kg}^{-1}\right)$ & 8.40 & 30.50 & 9.50 \\
\hline Total N (\%) & 0.34 & 2.90 & 1.80 \\
\hline $\mathrm{CEC}^{\mathrm{b}}\left(\mathrm{cmol} \mathrm{kg}^{-1}\right)$ & 6.62 & 10.83 & 10.17 \\
\hline $\mathrm{Clay}(\%)$ & 39.0 & 8.0 & 24.3 \\
\hline Silt $(\%)$ & 41.1 & 71.2 & 71.1 \\
\hline Sand (\%) & 19.9 & 20.8 & 4.6 \\
\hline $\mathrm{P}(\mathrm{mg} \mathrm{kg-1})$ & 3.21 & 25.20 & 10.80 \\
\hline
\end{tabular}

a Organic matter;

${ }^{\mathrm{b}}$ Cation Exchange Capacity.

Table 1. Basic physical-chemical properties of the soils. 


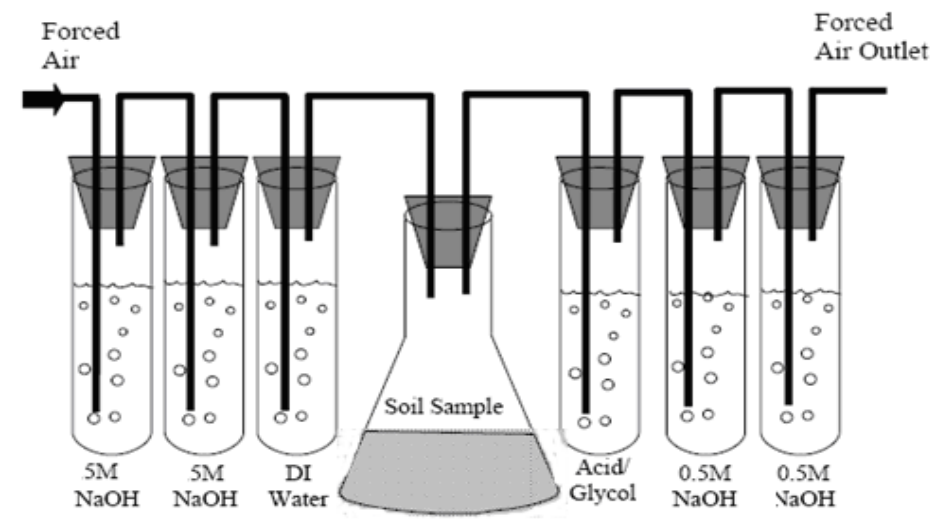

Fig. 2. Experimental set-up for monitoring bound residues of [pyrimidine-4,6-14C] ZJ0273 and [benzyl-U-14C] ZJ0273 during incubation with fresh soil.

\subsection{Extractable residue and parent compound}

The soil subsamples were transferred to $100-\mathrm{mL}$ polypropylene centrifuge tubes, and consecutively extracted with solvents with decreasing polarity by following a protocol similar to Mordaunt et al. (2005). The soil samples were shaken in each solvent $(50 \mathrm{~mL})$ for $24 \mathrm{~h}$, using the following solvents in a successive order: $0.01 \mathrm{~mol} / \mathrm{L} \mathrm{CaCl}_{2}$, acetonitrile/water $(9: 1, \mathrm{v} / \mathrm{v})$, methanol, and dichloromethane. At the end of the extraction period, the sample was centrifugated, supernatant collected and the final volume brought up to $50.0 \mathrm{~mL}$. From the extracts obtained from the first three extraction steps, an aliquot of $1.0 \mathrm{~mL}$ was withdrawn and mixed in $10.0 \mathrm{~mL}$ of scintillation cocktail $\mathrm{A}$ and analyzed for ${ }^{14} \mathrm{C}$ activity (dpm) using LSC. The dichloromethane extract from the final extraction step was condensed to dryness and then the residue was dissolved in $50 \mathrm{~mL}$ methanol. An aliquot of $1.0 \mathrm{~mL}$ was withdrawn for analysis of radioactivity. The radioactivity of total ER was the sum of radioactivity determined after each extraction step.

The $\mathrm{CaCl}_{2}$ extract was further adjusted to $\mathrm{pH} 3.0$ and partitioned with dichloromethane $(1: 1$, $\mathrm{v} / \mathrm{v})$ for three consecutive times. The dichloromethane phase was combined and condensed on a vacuum rotary evaporator at $40{ }^{\circ} \mathrm{C}$ until dry and the residue was pooled with those from the other three extraction steps. The combined supernatants were then condensed to about $1.0 \mathrm{~mL}$ on a vacuum rotary evaporator at $40{ }^{\circ} \mathrm{C}$ and centrifuged at $18,000 \mathrm{~g}$ for $15 \mathrm{~min}$. A $20-\mu \mathrm{L}$ aliquot was injected into a Waters HPLC and the eluted fraction corresponding to the parent compound peak was manually collected at the outlet for measurement of ${ }^{14} \mathrm{C}$. The HPLC system was composed of a Waters 600 multi-solvent delivery unit, a Waters 996 photodiode array (PDA) detector operating at $301 \mathrm{~nm}$ and $254 \mathrm{~nm}$, a Diamonsil $C_{18}$ column $(5-\mu \mathrm{m}, 250 \times$ $4.6 \mathrm{~mm}$, Dikma Technologies, Beijing, China), and a $\mathrm{C}_{18}$ guard column. The column temperature was maintained at $30^{\circ} \mathrm{C}$. The mobile phase $\mathrm{A}$ and $\mathrm{B}$ were made of $\mathrm{H}_{2} \mathrm{O}(\mathrm{HPLC}$ grade) and methanol, respectively, both containing $0.1 \%$ acetic acid. The elution was achieved at the flow rate of $1.0 \mathrm{~mL} \mathrm{~min}^{-1}$ using a gradient program (minutes/\% A: 0/80, 0$40 / 25,40-80 / 25,80-90 / 0$ ) and was collected and mixed with $10.0 \mathrm{~mL}$ of scintillation cocktail A. Their ${ }^{14} \mathrm{C}$ radioactivity was determined by LSC. 


\subsection{Bound residue}

After the sequential extraction, residual soils were left in a fume hood overnight to allow the evaporation of organic solvents and a 1.0-g aliquot of the air-dried soil was combusted to ${ }^{14} \mathrm{CO}_{2}$ on a biological oxidizer (OX-600, R.J. Harvey Instrument Corp., Hilldale, NJ, USA), followed by measurement of ${ }^{14} \mathrm{C}$ radioactivity by LSC to determine the amount of bound residue formed in soils. The total time of oxidation was $4.0 \mathrm{~min}$, the combustion temperature was $900{ }^{\circ} \mathrm{C}$ and the catalyzer temperature was $680^{\circ} \mathrm{C}$. The ${ }^{14} \mathrm{CO}_{2}$ evolved from combustion was trapped in $15 \mathrm{~mL}$ of scintillation cocktail B and the radioactivity was determined by Quantulus 1220 ultra-low Level liquid scintillation spectrometer (ULLLSS; Quantulus 1220, Wallac, Turku, Finland). The derived ${ }^{14} \mathrm{C}$ activity was defined as non-extractable or bound residue in this study. The ${ }^{14} \mathrm{C}$ recovery of the combustion method was determined to be $\geq$ $92.5 \%$ from analysis of samples spiked with known radioactivity of ${ }^{14} \mathrm{C}$ labeled ZJ0273.

\subsection{Measurement of mineralization to ${ }^{14} \mathrm{C}-\mathrm{CO}_{2}$}

At each sampling interval, ${ }^{14} \mathrm{CO}_{2}$ in the incubation flask was swept into the traps by purging each system with air for two hours to ensure that ${ }^{14} \mathrm{CO}_{2}$ was thoroughly trapped by the $\mathrm{NaOH}$ solution. The $\mathrm{NaOH}$ traps were exchanged with new solution, and the contents from the two used traps were combined and diluted into the volume of $50 \mathrm{~mL}$ with $\mathrm{H}_{2} \mathrm{O}$, after which $2.0 \mathrm{~mL}$ of the solution was mixed in $10 \mathrm{~mL}$ of scintillation cocktail A. After the samples were kept in dark for $24 \mathrm{~h}$ (to remove chemiluminescence), ${ }^{14} \mathrm{C}$ measurement was carried out on the ULLLSS, due to the relatively low radioactivity, which was calibrated with ${ }^{14} \mathrm{C}$-standards to correct for any quenching effect.

\subsection{MS analyses}

To elucidate the structures of the intermediates, LC-MS/MS analysis was carried out on a Micromass Quattro micro API ${ }^{\mathrm{TM}}$ with a HPLC detector and triple quadrupole mass analyzer for determining mass-to-charge ratio $(\mathrm{m} / \mathrm{z})$ for a wide variety of analytes (Waters, Milford, MA, USA). Control of the instruments and calculation was made using MassLynx V4.1 software (Waters). The instrument was operated in positive ESI ionization mode. Operating conditions were optimized by constantly introducing a standard solution of the abovementioned compounds to the HPLC flow via a T-connector with a split ratio of 1:1. The signal was optimized on the total ion current in MS mode by changing cone-, capillary-, extractor- and RF lens voltages in the source and resolution and ion-energy in the analyzer. At the same time the collision voltages and resolution in the second quadrupole were optimized. The structures of the intermediates were determined by comparing with mass spectral data of intermediate standards.

\subsection{Plant availability experiment}

Rice and corn were used for the plant availability assay. The soils containing BR from the above were mixed with fresh soils at three different ratios so that the initial contents of ${ }^{14} \mathrm{C}$ BR of ZJ0273 were $0.6,1.2$ and $1.8 \mathrm{nmol} \mathrm{g-1}$ dried soil corresponding to $11.2,22.4$, and $33.7 \mathrm{~Bq}$ $\mathrm{g}^{-1}$ dried soil. The mixed soils (130 g dry weight equivalent) were placed in 200-mL plastic pots for cultivation of corn and Petri dishes $(\mathrm{d}=12 \mathrm{~cm})$ for rice cultivation. After the soil moisture was adjusted to $60 \%$ and $80 \%$ of the maximum field water holding capacity for corn and rice, respectively, five germinated corn seeds were sown into each pot and 30 germinated rice seeds were sown into each Petri dish. The pots and Petri dishes without 
amendment of ${ }^{14} \mathrm{C}-\mathrm{BR}$ soil were similarly prepared and used as the control. Five replicates were set up for each treatment. Corn and rice seedlings were cultivated under the same greenhouse conditions $\left(25 / 20{ }^{\circ} \mathrm{C}\right.$, day/night; humidity, $80 \%$; light, $\left.12 \mathrm{~h} / 12 \mathrm{~h}\right)$, with irrigation every day. Visual inspection and photo taking were carried out at 5, 7 and $14 \mathrm{~d}$ after sowing. All seedlings were harvested at $14 \mathrm{~d}$ after sowing. The height of shoots was measured. Each seedling was divided into shoots and roots. The roots were washed with tap water. All the plant parts were dried at $60^{\circ} \mathrm{C}$ to a constant weight. Aliquots of five dried rice plants and individual corn plant were combusted on the biological oxidizer and the released ${ }^{14} \mathrm{CO}_{2}$ was absorbed in $15 \mathrm{~mL}$ liquid scintillation cocktail B. The radioactivity was measured by ULLLSS to estimate the amount of BR that was accumulated by the plant. The recovery efficiency of the above combustion procedure was $>95 \%$.

\subsection{Characterization of released residues}

After cultivation of rice and corn seedlings, the soils that were amended with BR at $1.8 \mathrm{nmol}$ $\mathrm{g}^{-1}$ were extracted using the procedure given in Section 2.4 and the extracts were further characterized for the composition of the released residues by the method of Section 2.7.

\subsection{Phytotoxicity assays}

The phytotoxicity of the released compounds from BR was evaluated using rice as the indicator species. The stock solutions of pure M1 $(38.1 \mathrm{mg})$, M3 $(27.6 \mathrm{mg})$ and ZJ0273 $(42.3 \mathrm{mg})$ were prepared in $1.0 \mathrm{~mL}$ dimethyl formamide $(1 \%)$, and diluted to a final volume of $100 \mathrm{~mL}$ with distilled water after addition of $1.0 \mathrm{~mL}$ isopropyl alcohol (1\%), $0.5 \mathrm{~mL}$ TW-80 (0.5\%) and $1.0 \mathrm{~mL}$ methanol $(1 \%)$. Five treatment solutions $(0.5,1,2.5,5$ and $10 \mu \mathrm{M})$ were prepared by diluting the stock solution with distilled water. After germination at $25{ }^{\circ} \mathrm{C}$ in Petri dishes containing filter papers moistened with distilled water, 20 seeds of rice were placed in the Petri dishes and treated with $9 \mathrm{~mL}$ of the compounds derived from the $\mathrm{BR}$ at the five concentrations. After cultivation in an illuminated incubator $\left(25 / 20{ }^{\circ} \mathrm{C}\right.$, day/night; humidity, $80 \%$; light, $12 \mathrm{~h} \mathrm{/12} \mathrm{h)} \mathrm{for} 7 \mathrm{~d}$, shoot height of rice seedlings was measured. Two different blanks were used. In blank 1 , rice seeds were exposed to solutions containing carrier-solvents but no ZJ0273 or its metabolites. In control 2, rice seeds were exposed to water only. Each treatment was replicated 5 times. The inhibition ratio (IR) was expressed as IR $=1$-(shoot height of treated rice / shoot height of control). A three parameter logarithm equation ( $y=a-$ $b^{*} \ln (x+c)$ ) was fitted to the data of inhibition ratio as a function of herbicide concentration by nonlinear regression using Origin 7.5 (Microcal Software, Northampton, MA).

\subsection{Statistical analysis}

All measurements were in three replicates and the arithmetic means and standard errors of means (means \pm SEM) were calculated from the repeated measurements. Significance between treatments was determined by a one-way analysis of variance (ANOVA) using Origin 6.0 (Microcal Software, Northampton, MA, USA).

\section{Results and discussion}

\subsection{Mass balance}

Mass balance was conducted to calculate the amount of ${ }^{14} \mathrm{CO}_{2}$ (mineralization), extractable residue, and bound residue for both ${ }^{14} \mathrm{C}$ labels. Throughout the entire incubation, mass 


\begin{tabular}{|c|c|c|c|c|c|}
\hline $\begin{array}{c}\text { Incubation } \\
\text { Days }\end{array}$ & Soil & $\mathrm{CaCl}_{2}$ & $\mathrm{CH}_{3} \mathrm{CN}: \mathrm{H}_{2} \mathrm{O}$ & $\mathrm{CH}_{3} \mathrm{OH}$ & $\mathrm{CH}_{2} \mathrm{Cl}_{2}$ \\
\hline \multirow{3}{*}{$5 d$} & $\mathrm{~S}_{1}$ & $13.8 \pm 5.3$ & $75.6 \pm 5.8$ & $8.2 \pm 0.9$ & $1.7 \pm 0.4$ \\
\hline & $\mathrm{S}_{2}$ & $11.9 \pm 0.9$ & $76.4 \pm 1.9$ & $7.2 \pm 0.8$ & $2.6 \pm 0.5$ \\
\hline & $\mathrm{S}_{3}$ & $16.7 \pm 3.2$ & $66.6 \pm 1.3$ & $9.97 \pm 2.5$ & $2.8 \pm 1$ \\
\hline \multirow{3}{*}{$10 d$} & $\mathrm{~S}_{1}$ & $11.4 \pm 3.9$ & $76.6 \pm 3.8$ & $9.6 \pm 0.3$ & $1.3 \pm 0.3$ \\
\hline & $\mathrm{S}_{2}$ & $11.8 \pm 2$ & $74.7 \pm 1.6$ & $8.5 \pm 0.6$ & $1.8 \pm 0.3$ \\
\hline & $\mathrm{S}_{3}$ & $14.1 \pm 1.4$ & $70.6 \pm 1.2$ & $8.4 \pm 1.4$ & $2.9 \pm 0.4$ \\
\hline \multirow{3}{*}{$20 d$} & $S_{1}$ & $12.6 \pm 3$ & $73.8 \pm 3.6$ & $9.5 \pm 0.9$ & $1.7 \pm 0.2$ \\
\hline & $S_{2}$ & $19.2 \pm 3$ & $61.7 \pm 2.5$ & 0.8 & $2.6 \pm 0.4$ \\
\hline & $\mathrm{S}_{3}$ & $23.5 \pm 9.8$ & $57.6 \pm 10.1$ & $8 \pm 1.2$ & $2.7 \pm 0.5$ \\
\hline \multirow{3}{*}{$30 d$} & $\mathrm{~S}_{1}$ & $15.5 \pm 4.9$ & $75.1 \pm 5.6$ & $6.4 \pm 0.3$ & $0.9 \pm 0.8$ \\
\hline & $\mathrm{S}_{2}$ & $36.6 \pm 5.3$ & $48.6 \pm 5.4$ & $5 \pm 0.9$ & $1.1 \pm 0.2$ \\
\hline & $\mathrm{S}_{3}$ & $35.8 \pm 7.5$ & $47.5 \pm 7.9$ & $6.2 \pm 0.9$ & $1.5 \pm 0.4$ \\
\hline \multirow{3}{*}{$45 \mathrm{~d}$} & $\mathrm{~S}_{1}$ & $20.2 \pm 7.8$ & $67.4 \pm 11.1$ & $5.2 \pm 0.7$ & $1.4 \pm 0.2$ \\
\hline & $\mathrm{S}_{2}$ & $34.6 \pm 7.9$ & $40.6 \pm 1$ & $4.2 \pm 0.1$ & $1.1 \pm 0$ \\
\hline & $\mathrm{S}_{3}$ & $39.8 \pm 2.7$ & $36.9 \pm 8.2$ & $5.5 \pm 1.1$ & $2 \pm 1.4$ \\
\hline \multirow{3}{*}{$60 d$} & $S_{1}$ & $30.4 \pm 7.4$ & $54.9 \pm 9.9$ & $3.8 \pm 1.3$ & $4 \pm 0.3$ \\
\hline & $\mathrm{S}_{2}$ & $34.9 \pm 0.6$ & $36 \pm 1.2$ & $4.2 \pm 0.5$ & $1.5 \pm 0.5$ \\
\hline & $\mathrm{S}_{3}$ & $32.6 \pm 1.9$ & $30.4 \pm 6.2$ & $3.8 \pm 0.5$ & $1.1 \pm 0.3$ \\
\hline \multirow{3}{*}{$75 d$} & $S_{1}$ & $24.4 \pm 7.3$ & $61 \pm 10.6$ & $4.6 \pm 1.5$ & $1.3 \pm 2.9$ \\
\hline & $S_{2}$ & $39.3 \pm 2.3$ & $26.7 \pm 1.2$ & $4.1 \pm 0.1$ & $1.5 \pm 0.2$ \\
\hline & $\mathrm{S}_{3}$ & $35.6 \pm 2.2$ & $24.5 \pm 5$ & $3.6 \pm 0.9$ & $2 \pm 1.3$ \\
\hline \multirow{3}{*}{$100 d$} & $\mathrm{~S}_{1}$ & $36.3 \pm 2.7$ & $35.9 \pm 6.3$ & $2.8 \pm 0.7$ & $0.9 \pm 0.4$ \\
\hline & $S_{2}$ & $33.8 \pm 2.4$ & $18 \pm 2.9$ & $3.6 \pm 0.6$ & $2.5 \pm 1.6$ \\
\hline & $\mathrm{S}_{3}$ & $30.8 \pm .38$ & $15.7 \pm 0.7$ & $3 \pm 0.2$ & $0.7 \pm 0.2$ \\
\hline
\end{tabular}

Table 2. Dissipation of extractable residue of [pyrimidine-4,6-14C] ZJ0273 and its metabolites after four-step extraction in soils 
balances as percentage of the initially added ${ }^{14} \mathrm{C}$ radioactivity were from $90.0 \pm 5.8 \%$ to $104.4 \pm 4.6 \%$, which indicated good mass recoveries for the procedures utilized in this study.

\subsubsection{Extractable residue (including parent compound and metabolites)}

It is manifested that extraction efficiency of ${ }^{14} \mathrm{C}$ activity immediately after application of ${ }^{14} \mathrm{C}$ labeled ZJ0273 ranged from 91.1 to $100.1 \%$ for [pyrimidine-4,6-14C] ZJ0273 and from 92.3 to $99.0 \%$ for [benzyl-U-14C] ZJ0273 in the three tested soils. During the first 30-d incubation, the fraction of total extractable residues (ER) from all extraction steps in the three soils was over $90 \%$ of the initially applied ${ }^{14} \mathrm{C}$ for [pyrimidine $-4,6-{ }^{14} \mathrm{C}$ ] ZJ0273. Nevertheless, total ER experienced a more dramatic downward trend during the next $30 \mathrm{~d}$ period, especially in $\mathrm{S}_{2}$ and $S_{3}$ (Table 2). The lag phase observed was similar to the phenomenon which was found in other studies (Roeth, 1986; Smith and Lafond, 1990). Pesticide degradation in soils was generally mediated by microorganisms and microbial degradation was commonly characterized by an initial lag phase due to adaptation of the microbes (Gevao et al., 2000). At $100 \mathrm{~d}$ after treatment, total ER declined to $75.9 \%$ for $S_{1}, 57.9 \%$ for $S_{2}$ and $50.2 \%$ for $S_{3}$. As a consequence, the level of total ER of [pyrimidine-4,6-14C] ZJ0273 in the acidic $\mathrm{S}_{1}$ soil was significantly higher than that in the neutral $S_{2}$ and alkaline $S_{3}$ soils $(p<0.05)$. Throughout the experiment, however, , there was no significant discrepancy in ER dissipation trends between the two ${ }^{14} \mathrm{C}$ labels $(p \geq 0.05)$ according to the comparison of data.

Extractable ${ }^{14} \mathrm{C}$ residue was further analyzed for the fraction of parent compound. Data analysis demonstrated that the fall of the parent compound in both [pyrimidine $-4,6-14 \mathrm{C}$ ] ZJ0273 and [benzyl-U-14C] ZJ0273 treatments complied with a first order decay model, with the regression coefficient $\mathrm{R}^{2}$ being 0.98 to $0.99(p<0.01$, data not shown). The estimated first-order half-lives were 51.0, 20.1 and $17.6 \mathrm{~d}$ for $S_{1}, S_{2}$ and $S_{3}$, respectively, for the [pyrimidine-4,6-14C] ZJ0273 treatment. Almost identical half-lives $(53.7 \mathrm{~d}, 20.4 \mathrm{~d}$ and $17.2 \mathrm{~d}$ for $S_{1}, S_{2}$ and $S_{3}$, respectively) were obtained for the [pyrimidine-4,6-14C] ZJ0273 treatment ( $p$ $<0.05)$. However, other scientists discovered diverse results in 2,4-D degradation by two multiple-position ${ }^{14} \mathrm{C}$-labels. For instance, Gaultier et al. (2008) used [ring-U-14C] 2,4-D (R2,4D) and [carboxyl-14 C] 2,4-D(C2,4-D) to measure degradation rates of 2,4-D, finding that rates of R2,4-D degradation in soils were limited more by sorption than rates of $\mathrm{C} 2,4-\mathrm{D}$ degradation. Smith and Muir (1980) and Xie et al. (1997) presented 15-20\% more [ring-U${ }^{14} \mathrm{C}$ ] 2,4-D bound to soil compared with [carboxyl- ${ }^{14} \mathrm{C}$ ] 2,4-D. In this study, for both labels, the dissipation of the parent compound was positively correlated with soil $\mathrm{pH}(p<0.001)$. Accordingly, ZJ0273 was more stable and resistant to transformation under acidic conditions. The similarities observed for the two labels offered evidence that the behavior of the parent compound was independent from the labeling position, which, as expected, was a direct validation of the rigorousness of the experimental procedures used in this study. The slower degradation in the acidic soil may attribute to the following factors. First and foremost, the propyl group of ZJ0273 is prone to break and thereby forming 4-(2- $(4,6-$ dimethoxypyrimidin-2-yloxy)benzylamino)benzoic acid under alkaline condition, while it is probably impossible to take place in acidic soil. Second of all, the acidic soil $S_{1}$ had a lower OM content than soils $S_{2}$ and $S_{3}$, and it is likely that the lower OM resulted in a reduced formation of bound residue between $\mathrm{OM}$ and the parent molecule, or a higher level of free parent compound. Last but not least, it is also likely that there were differences in microbial populations and makeup because of various soil $\mathrm{pH}$ conditions, which generated slower transformations in the acidic soil. 
At the first few sampling intervals, the majority of ER was extracted by acetonitrile-water, whereas relatively small fractions were from other extractions. Mordaunt et al. (2005) depicted that a significant large portion of $\mathrm{ER}$ was derived from $\mathrm{CaCl}_{2}$ extraction for atrazine, dicamba, and isoproturon, but from acetonitrile-water extraction for lindane and trifluralin. The difference was attributed to the differences in pesticide aqueous solubility. Specifically, the water solubility is $33 \mathrm{mg} \mathrm{L}^{-1}$ for atrazine, $6500 \mathrm{mg} \mathrm{L}^{-1}$ for dicamba, and 65 $\mathrm{mg} \mathrm{L}^{-1}$ for isoproturon, but much lower for lindane $\left(7.3 \mathrm{mg} \mathrm{L}^{-1}\right)$ and trifluralin $\left(0.2 \mathrm{mg} \mathrm{L}^{-1}\right)$. Compared with these pesticides, the aqueous solubility for ZJ0273 is substantially lower at $1.5 \mathrm{mg} \mathrm{L}^{-1}$ and the very low solubility would probably implicate the association of most ER with the acetonitrile-water extract during the initial phase of the incubation experiment. On the contrary, the fraction from the $\mathrm{CaCl}_{2}$ extraction step gradually rose as incubation time further increased. For instance, from $5 \mathrm{~d}$ to $100 \mathrm{~d}$ after the treatment, the fraction of $\mathrm{CaCl}_{2}$ extracted residue rocketed from $13.8 \%$ to $36.3 \%$ for [pyrimidine- $4,6-14 \mathrm{C}$ ] ZJ0273 (Table 2). Correspondingly, a similar phenomenon was found in the sequential extractions for the [benzyl-U-14C] ZJ0273 treatment. In our previous study, several metabolites, such as 2-(4,6dimethoxypyrimidin-2-yloxy)benzoic acid (M1), 4-(2-(4,6-dimethoxypyrimidin-2yloxy)benzylamino)benzoic acid (M2), 4-(2-(4,6-dimethoxypyrimidin-2yloxy)benzamido)benzoic acid (M3) and 4,6-dimethoxypyrimidin-2-ol and/or 4,6dimethoxypyrimidin-2(1H)-one (M4), were identified. All of these metabolites $(\log \mathrm{P}=1.40$ 4.11) were more polar than the parent compound $(\log \mathrm{P}=5.04)$, which induced the conclusion that the increased recoveries of ${ }^{14} \mathrm{C}$ by $\mathrm{CaCl}_{2}$ extraction suggested accumulation of polar metabolites in the soils.

\subsubsection{Mineralization}

The cumulative mineralization rates of [pyrimidine-4,6-14C] ZJ0273 and [benzyl-U-14C] ZJ0273 in three aerobic soil over time was present in Fig. 3. As can be seen from the graph that mineralization of both labels displayed a lag phase lasting from the beginning to about $20 \mathrm{~d}$ after the treatment. This lag phase coincided with what was observed in dissipation of extractable residues, suggesting that time was in need for the acclimatization of microbial degraders of this compound. After $20 \mathrm{~d}$, mineralization increased with incubation time, and appeared to accelerate towards the end of the incubation. Mineralized fractions of [pyrimidine-4,6-14C] ZJ0273 or [benzyl-U-14C] ZJ0273 were substantially higher in $\mathrm{S}_{2}$ and $\mathrm{S}_{3}$ than in $S_{1}$ at the same interval time. At the end of 100-d incubation, the total fraction mineralized in $S_{1}$ came least at less than $1.2 \%$ of the applied activity for [benzyl-U-14C] ZJ0273, with $S_{2}$ at $7.7 \%$ and $S_{3}$ at $9.9 \%$. In soils treated with [pyrimidine-4,6-14C] ZJ0273, at the end of $100-\mathrm{d}$ incubation, only $0.5 \%$ mineralization occurred in $S_{1}$, while the cumulative mineralization rate was $6.6 \%$ for $S_{2}$ and $5.0 \%$ for $S_{3}$. The overall mineralization rates of [pyrimidine-4,6-14C] ZJ0273 and [benzyl-U-14C] ZJ0273 were correlated with soil pH $(p<0.05)$ and organic matter content $(p<0.05)$. The soil $\mathrm{S}_{1}$ was more acidic $(\mathrm{pH} 4.20)$ and also had less organic matter than the other two soils (Table 1), which may have brought about limited microbial activity in this soil and hence a limited mineralization potential (Boivin et al., 2005). The slow mineralization of ZJ0273 in acidic soil and implications for risk assessment and management merit were further investigated. Mineralization to ${ }^{14} \mathrm{CO}_{2}$ was found to be consistently greater with [benzyl-U-14C] ZJ0273 than with [pyrimidine-4,6-14C] ZJ0273 in the same soil throughout the incubation. For instance, at the end of the 100-d incubation, the mineralized fractions of [pyrimidine-4,6-14C] ZJ0273 reached $6.6 \%$ for $S_{2}$, and $5.0 \%$ for $S_{3}$, 
while the corresponding fractions of [benzyl-U_-14C] ZJ0273 were $7.7 \%$ for $S_{2}$, and $9.9 \%$ for $S_{3}$. These differences suggested that, under the same conditions, mineralization of ZJ0273 involved more active ring cleavage at the benzyl ring than that at the pyrimidine ring.

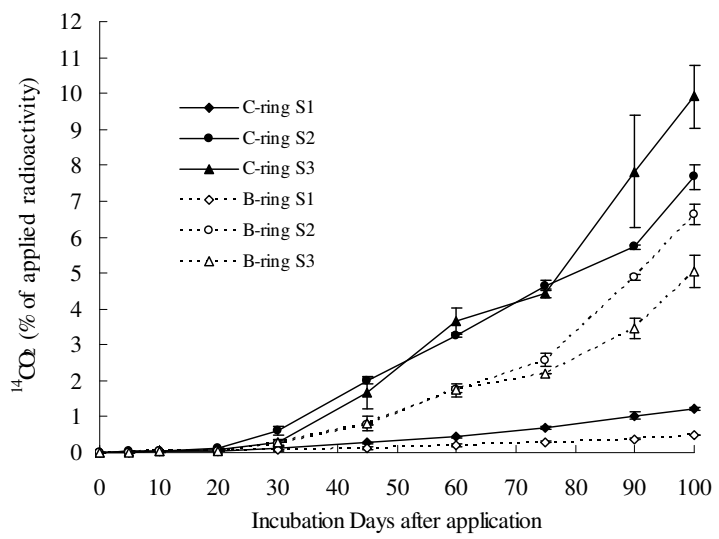

Fig. 3. Mineralization of [pyrimidine-4,6-14C] ZJ0273 and [benzyl-U-14C] ZJ0273 in three soils

\subsubsection{Bound residue}

The time-dependent accumulation of bound residue in soils for the two labels was presented in Fig. 4. The fraction of BR following treatment of [pyrimidine-4,6-14C] ZJ0273 increased rapidly in all three tested soils. The fraction of $B R$ in $S_{1}$ was found to be significantly smaller than in the other two soils $(p<0.01)$ and BR formation was correlated with soil $\mathrm{pH}(p<0.05)$. At the end of $100-\mathrm{d}$ incubation, BR represented around $35.3 \%$ of the initially applied ${ }^{14} \mathrm{C}$ in

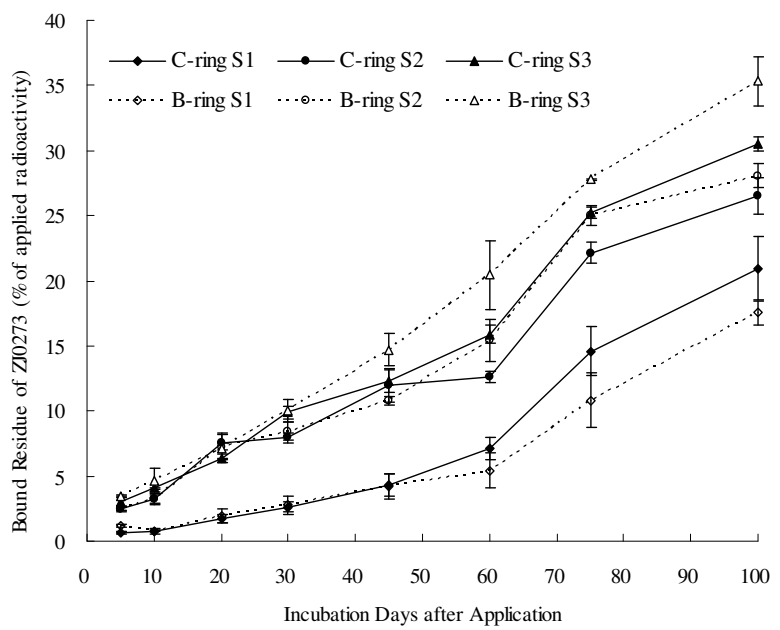

Fig. 4. Formation of bound residue after treatment of [pyrimidine-4,6-14C] ZJ0273 and [benzylU-14C] ZJ0273 in aerobic soils 
$S_{3}, 28.1 \%$ in $S_{2}$, and $17.5 \%$ in $S_{1}$, which were far lower than the $70 \%$ as described as the nonaccumulative criteria in the directive by CEC (1997). The formation of soil-bound residues for many pesticides has been reported to be mediated by the activities of soil microorganisms (Smith \& Philips, 1975; Haider, 1983; Krause et al., 1985). During the entire incubation, ANOVA analysis showed that there was no significant difference in BR formation between the two ${ }^{14} \mathrm{C}$ labels $(p \geq 0.05)$, which implies that formation of BR in soils involved parent compound and/or metabolites with both pyrimidine and benzyl rings, rather than metabolites with a single ring.

\subsection{Identification of degradation intermediates}

The highest radioactivity measured by HPLC and ULLLSS was found in the samples at 60 DAT. For the [pyrimidine-4,6-14C] ZJ0273 treatment, as shown in Fig. 5A and 5C, radioactivity was detected in five peaks at the retention time $\left(t_{R}\right)$ of $10,40,47,55$, and 70 $\mathrm{min}$. Other components that were not radio-labeled were not further identified. For [benzylU-14C] ZJ0273 treatment, only four radioactive peaks at the retention times $\left(t_{R}\right)$ of 40, 47, 55, and 70 min were detected while the peak at $9.80 \mathrm{~min}$ was absent (Fig. 5D). The radioactive intermediate peaks were found in both [pyrimidine-4,6-14C] ZJ0273 and [benzyl-U-14C] ZJ0273 treatments, suggesting that they could be possible degradation products of ZJ0273. Further structure analysis was conducted with the assistance of LC-MS/MS.

The parent ZJ0273 had a retention time of $70 \mathrm{~min}$, and its mass spectrum included ion fragments at $\mathrm{m} / \mathrm{z} 245\left(\mathrm{C}_{13} \mathrm{H}_{13} \mathrm{~N}_{2} \mathrm{O}_{3}\right), 424[\mathrm{M}+\mathrm{H}]^{+}$, and $446[\mathrm{M}+\mathrm{Na}]^{+}$. The selected ion chromatography of $\mathrm{m} / \mathrm{z} 424$ included the major ions (m/z, \%) of 364 (85), 245(100), and 185(10), which were consistent with the structure of standard ZJ0273 (Yang et al., 2009; Han et al., 2009a).

The peak at $47 \mathrm{~min}$ appeared in the HPLC trace and in the total ion chromatogram of degradation products of ZJ0273 (Fig. 5A and 5B), and was identified in the LC-MS/MS chromatogram. The mass spectrum of the intermediate at $47 \mathrm{~min}$ revealed $\mathrm{m} / \mathrm{z}$ $245\left(\mathrm{C}_{13} \mathrm{H}_{13} \mathrm{~N}_{2} \mathrm{O}_{3}\right), 382[\mathrm{M}+\mathrm{H}]^{+}$, and $404[\mathrm{M}+\mathrm{Na}]^{+}$, which was consistent with the structure of compound M1 with a molecular weight of 381. The selected ion chromatography of M1 included the major ions (m/z, \%) of 107 (35), 160 (30), 185 (20), 214 (15), 245 (100), and 319 (10) (Table 3). The fragment ion $(\mathrm{m} / \mathrm{z} 245)$ and two ion adducts $\left(\mathrm{m} / \mathrm{z} 382\left(\mathrm{C}_{20} \mathrm{H}_{20} \mathrm{~N}_{3} \mathrm{O}_{5}\right)\right.$, $\left.404\left(\mathrm{C}_{20} \mathrm{H}_{19} \mathrm{~N}_{3} \mathrm{O}_{5} \mathrm{Na}\right)\right)$ were simultaneously monitored, and the extracted ion chromatogram showed three peaks (m/z 382, 404 and 245), which rose and fell synchronously. The extracted ion chromatogram showed that this compound appeared to be ${ }^{14} \mathrm{C}-4-(2-(4,6-$ dimethoxypyrimidin-2-yloxy)benzylamino)benzoic acid. This was confirmed by comparing the retention time of this compound in HPLC with that of a standard of 4-(2- $(4,6-$ dimethoxypyrimidin-2-yloxy)benzylamino)benzoic acid.

Compound M2 that appeared at $55 \mathrm{~min}$ in the LC-MS chromatogram was identified. The mass spectrum of the metabolic intermediate at $55 \mathrm{~min}$ reveals $\mathrm{m} / \mathrm{z} 396[\mathrm{M}+\mathrm{H}]^{+}$, and $418[\mathrm{M}+\mathrm{Na}]^{+}$, which is consistent with the structure of compound M2. The selected ion of $\mathrm{m} / \mathrm{z} 396$ included the major ions (m/z, \%) of 107 (20), 139 (20), 185 (30), 230 (20), 245 (100), 300 (20), and $364(80)$ (Table 3). The fragment ion (m/z 245) and three ion adducts $(\mathrm{m} / \mathrm{z}$ $\left.107\left(\mathrm{C}_{7} \mathrm{H}_{7} \mathrm{O}\right), 185\left(\mathrm{C}_{11} \mathrm{H}_{9} \mathrm{~N}_{2} \mathrm{O}\right), 364\left(\mathrm{C}_{20} \mathrm{H}_{18} \mathrm{~N}_{3} \mathrm{O}_{4} \mathrm{Na}\right)\right)$ were monitored simultaneously at the optimal conditions, and the extracted ion chromatogram showed two peaks $(\mathrm{m} / \mathrm{z} 396$ and 418) consistent with the standard of M2. In addition, this compound was found radioactive in both treatments of [pyrimidine-4,6-14C] ZJ0273 and [benzyl-U-14C] ZJ0273, indicating that 
both the pyrimidine and benzyl rings were contained in the structure of M2. As M2 had a t of $55 \mathrm{~min}$ and matched the mass spectra of the standard, the intermediate compound was thus confirmed as ${ }^{14} \mathrm{C}-4$-(2-(4,6-dimethoxypyrimidin-2-yloxy)benzamido)benzoic acid.

\begin{tabular}{|c|c|c|l|}
\hline $\begin{array}{c}\text { Proposed } \\
\text { degradation } \\
\text { compound }\end{array}$ & $\mathrm{FW}$ & $\mathrm{t}_{\mathrm{R}}(\mathrm{min})$ & $\begin{array}{l}\text { MS spectrum ions of the selected ion }(\mathrm{m} / \mathrm{z}) \\
(\%, \text { abundance })\end{array}$ \\
\hline M1 & 381 & 47 & $107(35), 160(30), 185(20), 14(15), 245(100)$ \\
\hline M2 & 395 & 55 & $\begin{array}{l}107(20), 139(20), 185(30), 230(20), 245(100), \\
300(20), 364(80)\end{array}$ \\
\hline M3 & 276 & 40 & $107(45), 139(100), 153(75), 170(35), 259(35)$ \\
\hline M4 & 156 & 10 & $100(55), 125(30), 139(100), 141(30)$ \\
\hline
\end{tabular}

Table 3. HPLC-retention times $\left(t_{R}\right)$, mass spectra of ZJ0273 and its major degradation products in aerobic soils.

The peak for compound M3 appeared at $40 \mathrm{~min}$ in the chromatogram and in the total ion chromatogram of the LC-MS of ZJ0273 metabolites (Fig. 5A and 5B). The mass spectrum of the metabolite at $40 \mathrm{~min}$ revealed $\mathrm{m} / \mathrm{z} 259\left(\mathrm{C}_{13} \mathrm{H}_{11} \mathrm{~N}_{2} \mathrm{O}_{4}\right), 277[\mathrm{M}+\mathrm{H}]^{+}$, and $299[\mathrm{M}+\mathrm{Na}]^{+}(\mathrm{Table}$ 2). The selected ion of $\mathrm{m} / \mathrm{z} 277$ included the major ions (m/z, \%) of 107 (45), 139 (100), 153 (75), 170 (35), and 259 (35). The fragment ion (m/z 259) and two ion adducts $(\mathrm{m} / \mathrm{z} 277$ $\left.\left(\mathrm{C}_{13} \mathrm{H}_{13} \mathrm{~N}_{2} \mathrm{O}_{5}\right), 299\left(\mathrm{C}_{13} \mathrm{H}_{13} \mathrm{~N}_{2} \mathrm{O}_{5} \mathrm{Na}\right)\right)$ were monitored simultaneously. The intermediate was found radioactive in both [pyrimidine-4,6-14C] ZJ0273 and [benzyl-U-14C] ZJ0273 treatments, which showed that the structure of M3 contained both pyrimidine and benzyl rings. The HPLC retention time of this component was in accordance with the standard of 2-(4,6dimethoxypyrimidin-2-yloxy)benzoic acid. Comparison of the extracted ion chromatogram with the mass spectrum of the authentic standard further verified M3 as ${ }^{14} \mathrm{C}-2-(4,6-$ dimethoxypyrimidin-2-yloxy)benzoic acid with a molecular weight of 276.

The peak of compound M4 appeared at $10 \mathrm{~min}$ in the chromatogram and in the total ion chromatogram of LC-MS of ZJ0273 degradation products (Fig. 5A and 5B). The mass spectrum of this compound at $10 \mathrm{~min}$ revealed $\mathrm{m} / \mathrm{z} 157[\mathrm{M}+\mathrm{H}]^{+}$, which was consistent with the structure of compound M4 with a molecular weight of 156. The selected ion chromatograph of 157 included the major ions (m/z, \%) of 100 (55), 125 (30), 139 (100), and 141 (30) (Table 3). Since the compound was found only in the [pyrimidine-4,6-14C] ZJ0273 treatment, it should contain the pyrimidine ring. The extracted ion chromatogram, when compared with mass spectrum of an authentic standard confirmed the degradation product M4 to be 4,6-dimethoxypyrimidin-2-ol, a keto-enol tautomer of 4,6-dimethoxypyrimidin2(1H)-one, as described by Chang et al. (2007).

\subsection{Proposed degradation pathways}

As illustrated in Fig. 6, there were two possible metabolic pathways resulting in the degradation of ZJ0273. In all three aerobic soils, the parent compound was initially hydrolyzed and de-esterified by cleavage of the propyl group to form M1. Since the side chain carbon atom of the benzene ring tended to be oxidized abiotically or biotically, carbonylation occurred. After that, conjugation between the п orbital of the phenyl group or 

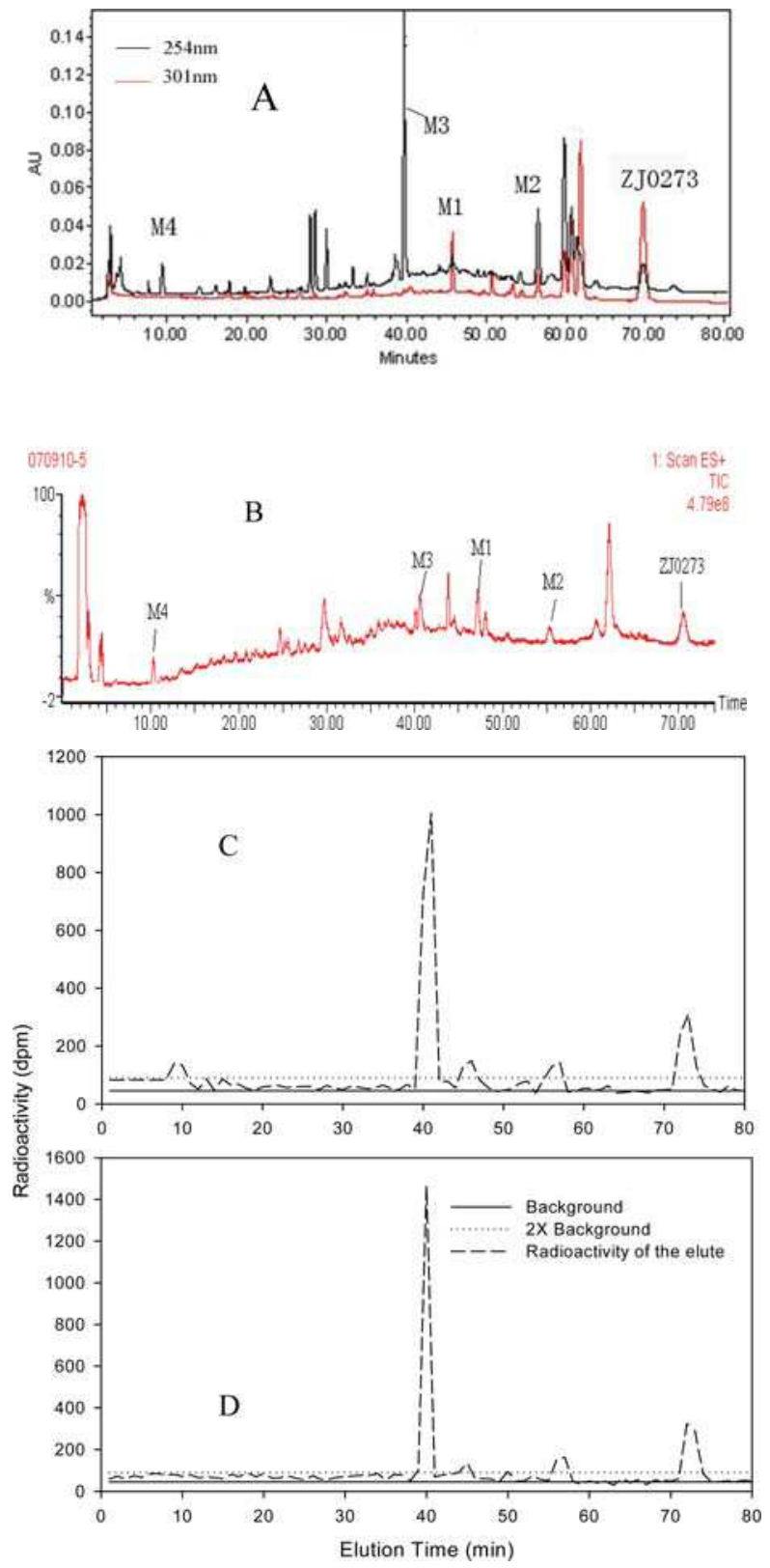

Fig. 5. Charts of HPLC, TIC of LC-MS, and radioactive chromatogram obtained from an extract of ${ }^{14} \mathrm{C}$-ZJ0273 degradation products. (A) HPLC chromatogram at the wavelength of $254 \mathrm{~nm}$ and $301 \mathrm{~nm}$; (B) LC-MS ESI+; (C) Radioactive chromatogram of elution of [pyrimidine-4,6-14C] ZJ0273 degradation products at 60 DAT; (D) Radioactive chromatogram of elution of [benzyl-U-14C] ZJ0273 degradation products at $60 \mathrm{DAT}$. 


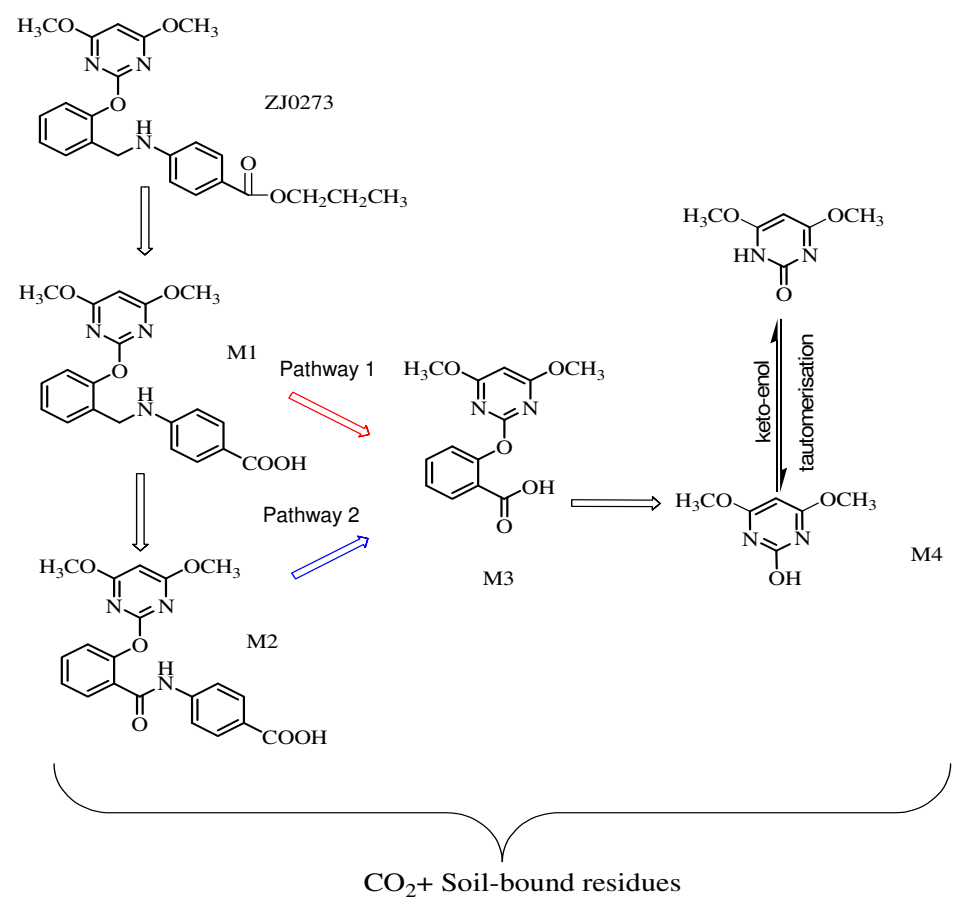

Fig. 6. Degradation pathways of ZJ0273 in aerobic soils. Pathway 1 showed the route of $\mathrm{ZJ0273} \rightarrow \mathrm{M} 1 \rightarrow \mathrm{M} 3 \rightarrow \mathrm{M} 4$; Pathway 2 followed the other route of $\mathrm{ZJ0273} \rightarrow \mathrm{M} 1 \rightarrow \mathrm{M} 2 \rightarrow \mathrm{M} 3 \rightarrow \mathrm{M} 4$.

the pyrimidine ring and the $\mathrm{p}$ orbital of the oxygen atom in the compound M3 was the dominant reaction. As the conjugation force of the pyrimidine ring was stronger than that of the phenyl ring, the fragments were supposed to be M4 and salicylic acid.Then M4 was ultimately decomposed to carbon dioxide. The second degradation pathway was also initiated by the hydrolysis to form M1. The carbon atom of the benzylamine group with higher activity was readily acylated to generate $\mathrm{M} 2$ with an amide group. In the intermediate M2, the amino group was an easy-to-leave group and was hydrolyzed with acid and/or base catalysts, which was followed by carboxylated with the phenyl ring and cleaved to form the main degradation product M3. The M3 was transformed as described in the first step to yield M4, and finally mineralized to $\mathrm{CO}_{2}$.

\subsection{Bioavailability and phytotoxicity of bound residue}

\subsubsection{Plant availability and phytotoxicity}

In order to explore plant availability and potential phytotoxicity of BR from ZJ0273, visual characterization and quantitative analysis including measurement of plant height, dry weight of shoot, root, and total plant of rice and corn seedlings were employed after exposure to soil BR fromZJ0273. Compared with the control, growth depression of rice seedlings by the BR was observed at the concentration of $1.8 \mathrm{nmol} \mathrm{g}-1$, while no inhibition occurred at the concentration of 0.6 or $1.2 \mathrm{nmol} \mathrm{g}^{-1}$ in all soils at $5 \mathrm{~d}$ after treatment (DAT). After growing in BR amended soils for $7 \mathrm{~d}$, growth of rice was significantly impeded at all concentration levels in the test soils and the suppression aggravated with growing 
concentrations. At $14 \mathrm{DAT}$, leaf chlorosis and growth inhibition of rice seedlings were recorded (Fig. 7a), which indicated a more pronounced inhibition compared with that at 7 DAT. Plant height, dry weights of shoot, root and the whole plant of rice seedlings decreased dramatically as the BR amendment rate increased in all the three soils at 14 DAT (Table 4), supporting the visual observations. These results demonstrated that ZJ0273 and/or its degradation products released from BR in the soils imposed severe phytotoxic impacts on the rice seedlings. Analysis of ${ }^{14} \mathrm{C}$ radioactivity in rice seedlings 14 DAT witnessed a rise in ${ }^{14} \mathrm{C}$ content in shoot, root and the whole plant with increasing amendment rates, coinciding with the drop in the plant height and dry weight (Table 5). It is suggested that the accumulation of the released chemicals from BR of ZJ0273 in the soils made great contribution in inhibiting plant growth. The total ${ }^{14} \mathrm{C}$ activity in the root reached a maximum in the soils amended with $\mathrm{BR}$ at $1.2 \mathrm{nmol} \mathrm{g}^{-1}$, indicating that absorption of BRderived chemicals was suppressed beyond this amendment rate (Table 5).

Over the whole process of cultivation, no significant visual growth depression of corn seedlings was observed 14 DAT in any treatment (Fig. 7b). Determination of plant height, dry weights of shoot, root and whole plant of corn seedlings further justified the visual observations (Table 5). Compared with the control, no significant inhibition was found in the plant height, dry weight of shoot, root and whole plant $(p>0.05$, Table 5). Quantification of ${ }^{14} \mathrm{C}$ radioactivity in different parts of corn seedling revealed that the total amount of ${ }^{14} \mathrm{C}$ in shoot and root increased with the rise of the BR amendment rate in the test soils (Table 6). The radioactivity of ${ }^{14} \mathrm{C}$ on a dry biomass basis was higher for the shoot of corn at a higher BR amendment rate, but no significant increase was gained for the root when the amendment rate increased from 1.2 to $1.8 \mathrm{nmol} \mathrm{g}^{-1}$ (Table 6).

\begin{tabular}{|c|c|c|c|c|c|}
\hline Soil & $\begin{array}{c}\text { Conc. } \\
\left(\mathrm{nmol} \mathrm{g}^{-1}\right)\end{array}$ & height $(\mathrm{cm})$ & $\begin{array}{c}\text { shoot } \\
(\mathrm{mg})\end{array}$ & $\begin{array}{c}\text { Root } \\
(\mathrm{mg})\end{array}$ & $\begin{array}{c}\text { Total weight } \\
(\mathrm{mg})\end{array}$ \\
\hline \multirow{4}{*}{$\mathrm{S}_{1}$} & 0 & $40.5 \pm 1.6$ & $152 \pm 13$ & $72 \pm 2$ & $227 \pm 13$ \\
\cline { 2 - 6 } & 0.6 & $43.3 \pm 1.3$ & $166 \pm 15$ & $79 \pm 8$ & $243 \pm 21$ \\
\cline { 2 - 6 } & 1.2 & $40.2 \pm 1.1$ & $155 \pm 13$ & $77 \pm 5$ & $232 \pm 17$ \\
\hline \multirow{4}{*}{$S_{2}$} & 1.8 & $40.4 \pm 1.5$ & $162 \pm 13$ & $80 \pm 5$ & $238 \pm 14$ \\
\cline { 2 - 6 } & 0 & $34.3 \pm 1.7$ & $120 \pm 14$ & $82 \pm 7$ & $197 \pm 10$ \\
\cline { 2 - 6 } & 1.2 & $34.8 \pm 1.1$ & $123 \pm 11$ & $88 \pm 6$ & $210 \pm 14$ \\
\hline \multirow{4}{*}{$S_{3}$} & 1.8 & $32.1 \pm 1.3$ & $110 \pm 10$ & $86 \pm 7$ & $208 \pm 16$ \\
\cline { 2 - 6 } & 0 & $38.2 \pm 2.0$ & $176 \pm 21$ & $74 \pm 6$ & $252 \pm 26$ \\
\cline { 2 - 6 } & 1.2 & $37.6 \pm 1.8$ & $169 \pm 19$ & $70 \pm 5$ & $240 \pm 25$ \\
\hline & 1.8 & $37.1 \pm 2.0$ & $168 \pm 22$ & $72 \pm 7$ & $248 \pm 21$ \\
\hline
\end{tabular}

Table 4. Bioavailability and phytotoxicity of bound residue derived from ZJ0273 on corn seedlings. 


\begin{tabular}{|c|c|c|c|c|c|}
\hline Soil & $\begin{array}{c}\text { Conc. } \\
(\mathrm{nmol} \mathrm{g}-1)\end{array}$ & $\begin{array}{c}\text { Height } \\
(\mathrm{cm})\end{array}$ & $\begin{array}{c}\text { Shoot } \\
(\mathrm{mg})\end{array}$ & $\begin{array}{c}\text { Root } \\
(\mathrm{mg})\end{array}$ & $\begin{array}{c}\text { Total } \\
\text { Weight }(\mathrm{mg})\end{array}$ \\
\hline \multirow{4}{*}{$\mathrm{S}_{1}$} & 0.0 & $26.0 \pm 0.2$ & $37.2 \pm 0.7$ & $7.3 \pm 0.2$ & $44.4 \pm 0.8$ \\
\cline { 2 - 6 } & 0.6 & $18.5 \pm 0.2$ & $25.4 \pm 0.3$ & $6.0 \pm 0.1$ & $31.5 \pm 0.6$ \\
\cline { 2 - 6 } & 1.2 & $17.4 \pm 0.2$ & $22.6 \pm 0.2$ & $5.3 \pm 0.1$ & $29.0 \pm 0.4$ \\
\cline { 2 - 6 } & 1.8 & $15.8 \pm 0.2$ & $19.2 \pm 0.3$ & $4.6 \pm 0.1$ & $24.5 \pm 0.4$ \\
\hline \multirow{3}{*}{$S_{2}$} & 0.0 & $26.5 \pm 0.3$ & $35.4 \pm 0.7$ & $7.7 \pm 0.2$ & $42.9 \pm 1.0$ \\
\cline { 2 - 6 } & 0.6 & $17.3 \pm 0.2$ & $19.1 \pm 0.5$ & $5.9 \pm 0.3$ & $25.2 \pm 0.8$ \\
\cline { 2 - 6 } & 1.2 & $14.9 \pm 0.1$ & $15.3 \pm 0.5$ & $5.2 \pm 0.1$ & $20.1 \pm 0.7$ \\
\hline \multirow{3}{*}{$S_{3}$} & 1.8 & $11.9 \pm 0.2$ & $12.6 \pm 0.7$ & $3.4 \pm 0.1$ & $16.0 \pm 0.7$ \\
\cline { 2 - 6 } & 0.0 & $25.5 \pm 0.3$ & $38.9 \pm 1.0$ & $6.9 \pm 0.2$ & $45.9 \pm 1.2$ \\
\cline { 2 - 6 } & 0.6 & $20.5 \pm 0.4$ & $29.3 \pm 0.6$ & $5.6 \pm 0.1$ & $32.0 \pm 1.4$ \\
\cline { 2 - 6 } & 1.2 & $14.8 \pm 0.2$ & $17.5 \pm 0.6$ & $4.9 \pm 0.1$ & $22.6 \pm 0.8$ \\
\hline
\end{tabular}

Table 5. Bioavailability and phytotoxicity of ZJ0273 bound residue on rice seedlings.

After plant cultivation and the subsequent extraction in Section 2.4, decreases in the radioactivity of ${ }^{14} \mathrm{C}$ in the whole soil indicated the fraction of BR released. The fractions of ${ }^{14} \mathrm{C}$ released after rice planting were $68.3 \%, 57.0 \%$, and $61.1 \%$ of the applied activity, respectively, for $S_{1}, S_{2}$ and $S_{3}$ amended with $B R$ at $1.8 \mathrm{nmol} \mathrm{g}^{-1}$. The released amounts were considerably greater than those in the corresponding soils grown with corn, which ranged from $32.6 \%$ to $38.9 \%$. The inhibition caused by the BR on rice seedlings in the different soils followed the order $S_{1}>S_{3}>S_{2}$, similar to the order for the fractions of ${ }^{14} \mathrm{C}$ released. The interactions between pesticides, along with their metabolites, and soils are extremely complicated and may change with soil $\mathrm{pH}$, microbial community and soil enzyme activity (Khan, 1982; Dec \& Bollag, 1988). During the cultivation, different soil conditions for corn and rice may have contributed to the different release rates of BR. Furthermore, much larger amounts of the released ${ }^{14} \mathrm{C}$ were absorbed into the corn plants than rice seedlings, despite the amount of ${ }^{14} \mathrm{C}$ per dry biomass was smaller for corn. All in all, the lower accumulation rates of BR-derived residues on a biomass basis may have led to the insignificant injury in corn seedlings.

\subsubsection{Characterization of released residues}

Extractable products from soils amended with BR after planting of rice or corn were resolved on HPLC and the radioactivity was measured in the eluted fractions. The retention times of the three radioactive peaks coincided with those for the authentic standards for parent ZJ0273 (70 $\mathrm{min})$, M1 (47 $\mathrm{min})$ and M3 (40 min). Both M1 and M3 are degradation products that were previously identified upon degradation of ZJ0273 in soil. The metabolite M1 was a hydrolysis product of ZJ0273 and its further metabolism may lead to the formation of M3, which belongs to the first degradation pathway mentioned above. ZJ0273 and its degradation products may bind to the soil through physical and/or chemical interactions such as van der Walls forces, ligand exchange, charge-transfer complexes, hydrophobic partitioning, and covalent bonding. The formed soil BR of ZJ0273 could be 
Environment Behavior and Fate of a

Novel Pyrimidynyloxybenzoic Herbicide ZJ0273 in Aerobic Soil

\begin{tabular}{|c|c|c|c|c|c|}
\hline Soil & $\begin{array}{c}\text { Conc. } \\
\left(\mathrm{nmol} \mathrm{g}^{-1}\right)\end{array}$ & $\begin{array}{c}\text { Shoot } \\
\left(\mathrm{Bq} \mathrm{g}^{-1}\right)\end{array}$ & $\begin{array}{c}\text { Root } \\
\left(\mathrm{Bq} \mathrm{g}^{-1}\right)\end{array}$ & $\begin{array}{c}\text { Shoot } \\
(\mathrm{Bq})\end{array}$ & $\begin{array}{c}\text { Shoot } \\
(\mathrm{Bq})\end{array}$ \\
\hline \multirow{4}{*}{$\mathrm{S}_{1}$} & 0 & 0 & 0 & 0 & 0 \\
\cline { 2 - 6 } & 0.6 & $6.8 \pm 0.4$ & $18.0 \pm 1.6$ & $1.2 \pm 0.1$ & $1.3 \pm 0.1$ \\
\cline { 2 - 6 } & 1.2 & $12.7 \pm 0.8$ & $38.7 \pm 2.6$ & $2.0 \pm 0.2$ & $2.8 \pm 0.2$ \\
\cline { 2 - 6 } & 1.8 & $16.2 \pm 0.9$ & $38.4 \pm 2.6$ & $2.7 \pm 0.2$ & $3.5 \pm 0.4$ \\
\hline \multirow{4}{*}{$S_{2}$} & 0 & 0 & 0 & 0 & 0 \\
\cline { 2 - 6 } & 0.6 & $24.4 \pm 3.4$ & $31.9 \pm 2.3$ & $2.3 \pm 0.3$ & $3.8 \pm 0.4$ \\
\cline { 2 - 6 } & 1.2 & $45.6 \pm 4.1$ & $62.9 \pm 2.8$ & $3.3 \pm 0.4$ & $6.3 \pm 0.6$ \\
\hline \multirow{4}{*}{$S_{3}$} & 1.8 & $75.5 \pm 6.6$ & $62.8 \pm 6.3$ & $6.9 \pm 0.6$ & $8.1 \pm 1.2$ \\
\cline { 2 - 6 } & 0 & 0 & 0 & 0 & 0 \\
\cline { 2 - 6 } & 0.6 & $11.5 \pm 0.7$ & $30.0 \pm 1.7$ & $2.2 \pm 0.2$ & $2.0 \pm 0.2$ \\
\cline { 2 - 6 } & 1.2 & $16.5 \pm 1.0$ & $45.1 \pm 2.5$ & $2.7 \pm 0.2$ & $2.8 \pm 0.3$ \\
\hline
\end{tabular}

Table $6 .{ }^{14} \mathrm{C}$ radioactivity in corn seedlings.
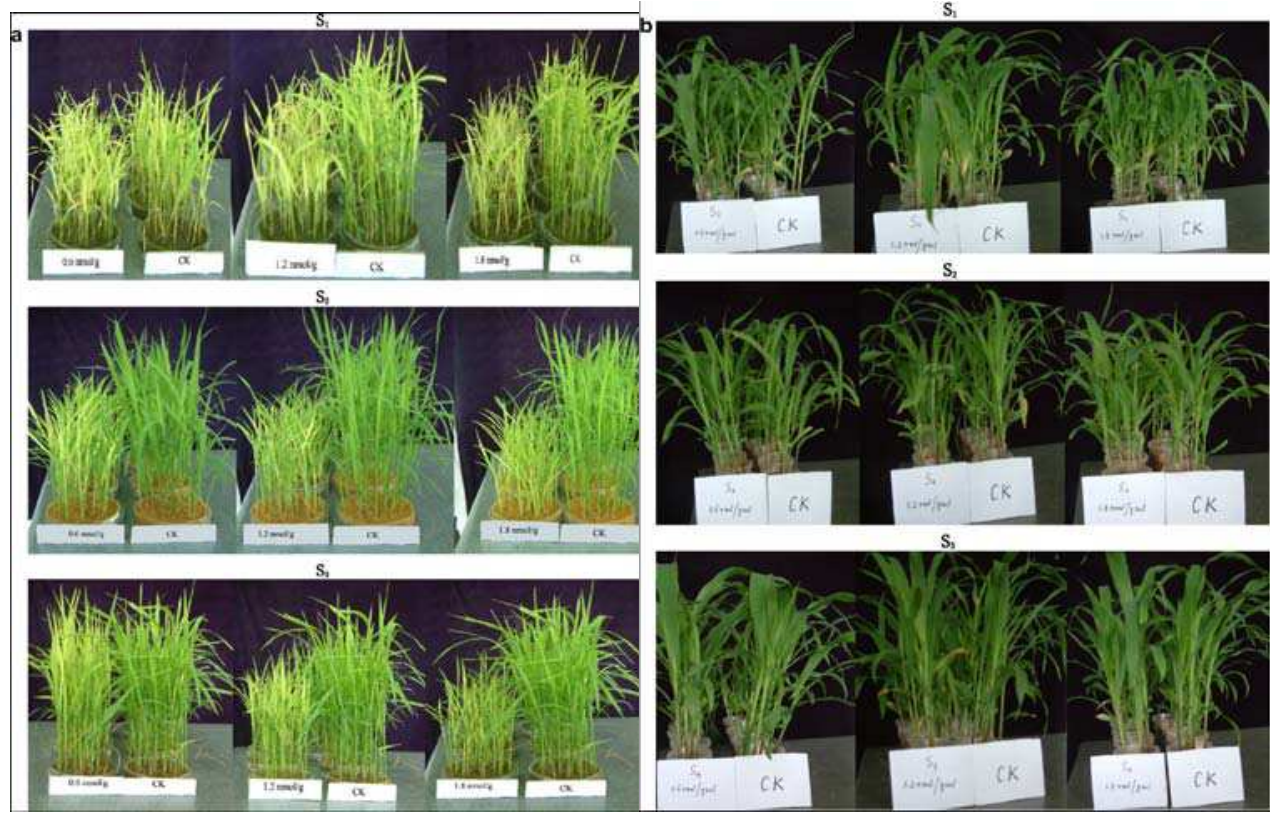

Fig. 7. (a). Effects of bound residues of ${ }^{14} \mathrm{C}-Z \mathrm{JJ} 0273$ on growth of rice seedlings in soils at $14 \mathrm{~d}$ after application; (b). Effects of bound residues of ${ }^{14} \mathrm{C}-\mathrm{ZJ} 0273$ on growth of corn seedlings in soils at $14 \mathrm{~d}$ after application. 
released by physico-chemical mechanisms or through biochemical processes. However, in this study it was found that only M1, M3 and ZJ0273 were released from the soil BR upon planting and the relative ratios of the three compounds varied with soil types and plant types. In the extractable residues, ZJ0273 and its degradation products M1 and M3 constituted $6.9-10.7 \%, 14.8-17.7 \%$, and $68.0-77.1 \%$, respectively (see Fig. 8), for soils grown with corn, as compared with $15.1-31.0 \%, 25.6-39.8 \%$, and $38.3-45.1 \%$ in rice growing soils. In all soils, M3 was the dominant compound released from soil BR derived from ZJ0273.

\begin{tabular}{|c|c|c|c|c|c|}
\hline Soil & $\begin{array}{c}\text { Conc. } \\
\left(\text { (mol g- }^{-1}\right)\end{array}$ & $\begin{array}{c}\text { Shoot } \\
\left(\mathrm{Bq} \mathrm{g}^{-1}\right)\end{array}$ & $\begin{array}{c}\text { Root } \\
\left(\mathrm{Bq} \mathrm{g}^{-1}\right)\end{array}$ & $\begin{array}{c}\text { Shoot } \\
(\mathrm{Bq})\end{array}$ & $\begin{array}{c}\text { Root } \\
(\mathrm{Bq})\end{array}$ \\
\hline \multirow{4}{*}{$\mathrm{S}_{1}$} & 0 & 0 & 0 & 0 & 0 \\
\cline { 2 - 6 } & 0.6 & $35.7 \pm 0.9$ & $61.9 \pm 2.6$ & $0.52 \pm 0.03$ & $0.23 \pm 0.01$ \\
\cline { 2 - 6 } & 1.2 & $71.5 \pm 2.6$ & $100.1 \pm 5.3$ & $1.03 \pm 0.08$ & $0.31 \pm 0.02$ \\
\cline { 2 - 6 } & 1.8 & $110.7 \pm 4.4$ & $129.1 \pm 2.6$ & $1.28 \pm 0.08$ & $0.32 \pm 0.01$ \\
\hline \multirow{4}{*}{$S_{2}$} & 0 & 0 & 0 & 0 & 0 \\
\cline { 2 - 6 } & 0.6 & $61.5 \pm 1.6$ & $214.0 \pm 6.3$ & $1.35 \pm 0.07$ & $1.33 \pm 0.07$ \\
\cline { 2 - 6 } & 1.2 & $130.3 \pm 2.0$ & $373.7 \pm 15.1$ & $1.97 \pm 0.07$ & $2.15 \pm 0.08$ \\
\hline \multirow{4}{*}{$S_{3}$} & 1.8 & $203.5 \pm 8.2$ & $387.9 \pm 8.0$ & $2.59 \pm 0.10$ & $1.36 \pm 0.07$ \\
\cline { 2 - 6 } & 0 & 0 & 0 & 0 & 0 \\
\cline { 2 - 6 } & 0.6 & $27.4 \pm 1.2$ & $63.3 \pm 2.3$ & $0.75 \pm 0.04$ & $0.36 \pm 0.02$ \\
\cline { 2 - 6 } & 1.2 & $66.1 \pm 2.6$ & $101.1 \pm 2.0$ & $1.31 \pm 0.07$ & $0.51 \pm 0.02$ \\
\hline & 1.8 & $114.3 \pm 5.2$ & $121.2 \pm 3.5$ & $1.62 \pm 0.12$ & $0.40 \pm 0.02$ \\
\hline
\end{tabular}

Table $7 .{ }^{14} \mathrm{C}$ radioactivity in rice seedlings.

\subsubsection{Phytotoxicity of the released compounds}

Phytotoxicity of ZJ0273 and the two identified compounds 4-(2-(4,6-dimethoxypyrimidin-2yloxy)benzylamino)benzoic acid and 2-(4,6-dimethoxypyrimidin-2-yloxy)benzoic acid was further evaluated by measurement of the shoot height of rice seedlings exposed to solutions containing these compounds. No significant differences were found in the shoot height of rice seedlings exposed to control 1 and control 2 solutions. Thus, the inhibition ratio was calculated based on control 2. No significant inhibition effect was observed on rice by ZJ0273 at 0.5 and $1 \mu \mathrm{M}$ (see Fig. 8). However, the plant height decreased at $2.5 \mu \mathrm{M}$ of ZJ0273 and the inhibition reach $28.9 \%$ at $10 \mu \mathrm{M}$. The inhibition effect caused by M1 and M3 both increased with the growth of concentration. At the same concentration, the inhibition rate followed the order of 2-(4,6-dimethoxypyrimidin-2-yloxy)benzoic acid (M3) > 4-(2-(4,6dimethoxypyrimidin-2-yloxy)benzylamino)benzoic acid (M1) > ZJ0273, with the inhibition rate at $10 \mu \mathrm{M}$ reaching $75.5 \%, 86.0 \%$, and $28.9 \%$ for M1, M3, and ZJ0273, respectively. The IC50 values of M1, M3 and ZJ0273, defined by nonlinear regression of rice shoot height over the treated doses, were assessed to be 1.93, 0.49 and $33.16 \mu \mathrm{M}$, respectively (see Fig. 8). Results of the phytotoxicity assay suggested that M1 and M3 were more biologically active than the parent ZJ0273 against rice. It may be further concluded that it was the degradation products of ZJ0273, M3 in particular, that possibly imposed the inhibition effect on the growth of rice seedlings. 


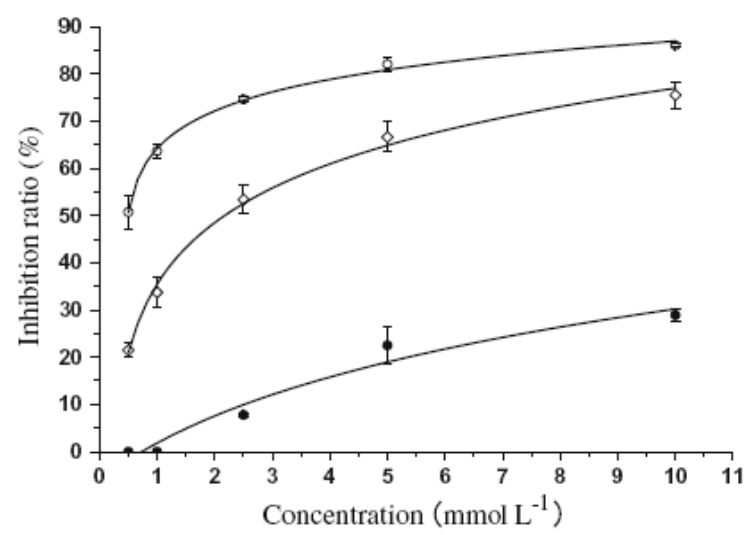

Fig. 8. Inhibition of ZJ0273 $(-\mathrm{d}-, \mathrm{y}=-23.58+21.45 * \ln (\mathrm{x}+2.27), \mathrm{R} 2=0.9643), \mathrm{M} 1(-\mathrm{e}-, \mathrm{y}=$ $\left.37.69+17.13 * \ln (x+0.12), R^{2}=0.9954\right)$ and M3 (-s-, $\left.y=68.12+8.30 * \ln (x-0.38), R^{2}=0.9969\right)$ on growth of rice seedling measured as reductions in shoot height.

Previous studies have shown that ZJ0273 inhibits the synthesis of the branched-chain amino acids in a susceptible plant in vivo and the inhibition effect is counteracted by the addition of branched-chain amino acids, while no inhibition is detected under in vitro conditions. These results suggest that ZJ0273 is a pro-herbicide and it is the metabolites of ZJ0273 in the plant that contribute to the inhibition on ALS (Chen et al., 2005). Far more severe inhibition effect of M3 on ALS was studied in preliminary studies (unpublished). The IC50 of M3 on the ALS of the etiolated pea shoots was estimated to be $0.39 \mu \mathrm{M}$ (Yukio et al., 1996). Therefore, the cause of phytotoxicity to rice from soil BR of ZJ0273 may be attributed to the release of ZJ0273, M1, and M3 from the soil BR and the subsequent inhibition on the biosynthesis of amino acids in plants due to the inhibition of ALS primarily by M3.

\section{Conclusion}

As a novel acetolactate synthase potential inhibitor, ZJ0273 had short to intermediate persistence in aerobic soils, with half-lives ranging from 17.2 to $53.7 \mathrm{~d}$ for the parent molecule. The disappearance of the parent compound was accompanied with production of metabolites, formation of $\mathrm{BR}$ and mineralization to $\mathrm{CO}_{2}$. The overall transformation of ZJ0273 appeared to closely rely on soil properties such as $\mathrm{pH}$ and organic matter content. In an acidic soil with low organic matter content, ZJ0273 was degraded much slower with limited mineralization and reduced formation of BR. Use of ${ }^{14} \mathrm{C}$ labels at different positions provided similar and hence confirmatory information on the behavior of the parent compound and formation of BR. However, mineralization of [benzyl-U-14C] ZJ0273 was consistently greater than that of [pyrimidine-4,6-14C] ZJ0273under the same conditions, suggesting that ring cleavage at the benzyl ring was more active than the pyrimidine ring. Judging from the information of BR and mineralization, ZJ0273 met the non-accumulative criteria as stated in the directives by the Commission of the European Communities (BR < $70 \%$ of the initial dose after $100 \mathrm{~d}$ with mineralization to $\mathrm{CO}_{2}$ at $\left.>5 \%\right)$.

In this study, four aromatic intermediates of ZJ0273, 4-(2-(4,6-dimethoxypyrimidin-2yloxy)benzylamino)benzoic acid, 4-(2-(4,6-dimethoxypyrimidin-2-yloxy)benzamido)benzoic 
acid, 2-(4,6-dimethoxypyrimidin-2-yloxy)benzoic acid, and 4,6-dimethoxypyrimidin-2-ol, were identified. Two possible metabolic pathways could lead to the degradation of ZJ0273.On the one hand, in all three aerobic soils, the parent compound was initially hydrolyzed and de-esterified by cleavage of the propyl group to form 4-(2- $(4,6-$ dimethoxypyrimidin-2-yloxy)benzylamino)benzoic acid. Since the side chain carbon atom of the benzene ring tended to be oxidized abiotically or biotically, carbonylation occurred. Conjugation was the dominant reaction in the compound 2-(4,6-dimethoxypyrimidin-2yloxy)benzoic acid, which was ultimately decomposed to carbon dioxide. On the other hand, the degradation pathway was also initiated by the hydrolysis to 4-(2- $(4,6-$ dimethoxypyrimidin-2-yloxy)benzylamino)benzoic acid, which was readily acylated to generate 4-(2-(4,6-dimethoxypyrimidin-2-yloxy)benzamido)benzoic acid, then, to form the main degradation product 2-(4,6-dimethoxypyrimidin-2-yloxy)benzoic acid, which then was transformed to yield 4,6-dimethoxypyrimidin-2-ol, and finally mineralized to $\mathrm{CO}_{2}$.

Meanwhile, plant availability and phytotoxicity of soil bound residues of herbicide ZJ0273 showed that only ZJ0273 and its two degradation products M1 and M3 were identified in the extract of the released residues from BR after planting of corn or rice. Phytotoxicity assay of the three compounds revealed that M3 played a dominant role in the inhibition effect on the growth of rice seedlings. In the extractable residues released from BR, the most biologically active M3 made up of the largest fraction in all soils. Therefore, it may be concluded that the main cause of phytotoxicity from exposure to soil BR of ZJ0273 is related to the release of ZJ0273 and its degradation products and the subsequent inhibition on ALS by M3. The elevated accumulation of ${ }^{14} \mathrm{C}$ on a biomass basis in rice as compared with corn provided an explanation to the occurrence of phytotoxicity only in the former. Results from this study clearly showed that when a field previously treated with ZJ0273 is subsequently used for planting of rice, there would be an increased likelihood for herbicide induced phytotoxicity. This hypothesis is valuable since it helps to select the succeeding rotation crops to prevent yield losses.

All these findings provided the basic information that might be useful for assessing the factors related to the environmental fate and behavior of this commonly used herbicide. However, absorption, translocation, distribution, residue in the oilseed rape metabolism, and mode of action of the herbicide still remain unknown, which are well worth studying in the near future.

\section{References}

Boivin, A.; Amellal, S.; Schiavon, M.; Genuchten, M.T. (2005). 2,4-Dichlorophenoxyacetic acid $(2,4-\mathrm{D})$ sorption and degradation dynamics in three agricultural soils. Environ. Pollut., 138, 92-99.

Chen, J.; Yuan, J.; Liu, J.D.; Fu, Q.M.; Wu, J. (2005). Mechanism of action of the novel herbicide ZJ0273. Acta Phytophylacica Sinica, 32, 48-52.

Commission of the European Communities. (1997). European Commission Directive 97/57, establishing Annex VI (Uniform Principles) to Directive 91/414. Commission of the European Communities, Directorate-General for Agriculture, DG VI B II-1, Brussels, Belgium.

Craven, A. (2000). Bound residues of organic compounds in the soil: the significance of pesticide persistence in soil and water: a European regulatory view. Environ. Pollut., $108,15-18$. 
Craven, A.; Hoy, S. (2005). Pesticide persistence and bound residues in soil-regulatory significance. Environ. Pollut., 133, 5-9.

Dec, J.; Bollag, J.M. (1988). Microbial release and degradation of cathecol and chlorophenols bound to synthetic humic acid. Soil Sci. Soc. Am. J., 52, 1366-1371.

Environmental Protection Agency. Final Report to the U.S. Environmental Protection Agency Washington, D.C. (Topic Area: Environmental Chemistry 98-NCERQAA3), 2002. p. 93.

Fent, G.; Hein, W.J.; Moendel, M.J.; Kubiak, R. (2003). Fate of ${ }^{14}$ C-bisphenol A in soils. Chemosphere, 51,735-746.

Gaultier, J.; Farenhorst, A.; Cathcart, J.; Goddard, T. (2008). Degradation of [carboxyl-14C] 2,4-D and [ring-U-14C] 2,4-D in 114 agricultural soils as affected by soil organic carbon content. Soil Biol. Biochem., 40, 217-227.

Gee, G.W.; Bauder, J.W. (1986). Particle-size analysis. In Methods of Soil Analysis, Part 1, Physical and Mineralogical Methods; Klute, A., Ed.; Soil Science Society of America: Madison, WI, pp. 383-412.

Gevao, B.; Semple, K.T.; Jones, K.C. (2000). Bound pesticide residues in soils: a review. Environ. Pollut., 108, 3-14.

Haider, K. (1983). Abstracts. IUPAC Pesticide Chemistry. Miyamoto et al. (Eds.). p. 177-182, Pergamon Press, New York.

Khan, S.U. (1982). Bound pesticide residues in soil and plants. Residue Rev., 81, 1-25.

Krause, A.; Hancock, W.G.; Minard, R.D.; Freyer, A.J.; Honeycutt, R.C.; LeBaron, H.M.; Paulson, D.L.; Lui, S.Y.; Bollag, J.M. (1985). Microbial transformation of the herbicide metolachlor by a soil actinomycete. J. Agri. Food Chem., 33, 584-589.

Langenbach, T.; Schroll, R.; Paim, S. (2000). Fate and distribution of ${ }^{14} \mathrm{C}$-atrazine in a tropical oxisol. Chemosphere, 40, 449-455.

Langenbach, T.; Schroll, R.; Scheunert, I. (2001). Fate of the herbicide ${ }^{14}$ C-terbuthylazine in Brazilian soils under various climatic conditions. Chemosphere, 45, 387-398.

Lu, L.; Chen, J.; Wu, J.; Ling, W.; Mao, L.S.; Li, M.Z.; Cai, X.; Peng, W.L.; Wu, Y,; Wu, S.G.; Wang, H.J.; Wang, G.C.; Cui, H.; Han, S.D.; Qiu, W.L.; Wang, Y.H. (2004). 2Pyrimidinyloxy-N-arylbenzylamine derivatives, their processes and uses. U.S. patent $6800590 \mathrm{~B} 2$.

Mordaunt, C.J.; Gevao, B.; Jones, K.C.; Semple, K.T. (2005). Formation of non-extractable pesticide residues: observations on compound differences, measurement and regulatory issues. Soil Biol. Biochem., 133, 25-34.

Moyer, S.R.; Esau, R.; Kozub, G.C. (1990). Chlorsulfuron persistence and response of nine rotational crop in alkaline soils of Southern Alberta. Weed Technol., 4, 543-548.

Nelson, D.W.; Sommers, L.E. (1982). Total carbon, organic carbon, and organic matter. In: Methods of Soil Analysis, Page, A.L., Miller, R.H., Keeney, D.R. (Eds.), Part 2, Chemical and Microbiological Properties, pp. 539-579, American Society of Agronomy, Madison, Wisconsin.

Roeth, F.W. (1986). Enhanced herbicide degradation in soil with repeat application. Rev. Weed Sci., 2, 45-65.

Smith, A.E.; Lafond, G.P. (1990). Effects of long-term phenoxyalk-anoic acid field applications on the rate of microbial degradation. ACS Symposium Series, 426, 14-22. 
Smith, A.E.; Muir, D.C.G. (1980). Determination of extractable and nonextractable radioactivity from prairie soils treated with carboxyl- and ring-labelled [14C]2,4-D. Weed Research, 20, 123-129.

Smith, A.E.; Philips, D.V. (1975). Degradation of alachlor by Rhizoctonia solani. Agron. J., 7, 347-349.

Tang, Q.H.; Chen, J.; Lu, L. (2005). An innovative research for novel rape herbicide ZJ0273. Chin. J. Pestic. Sci., 44, 496-502.

Vithala, R.; White, C.K. (1996). Aerobic metabolism of flupropacil in sandy loam soil. Pestic. Sci., 47, 235-240.

Walker, S.S.; Robinson, G.R.; Hargreaves, P.A. (1997). Weed control with atrazine and chlorsulfuron is determined by herbicide availability and persistence in soils. Aust. J. Agric. Res., 48, 1003-1009.

Xie, H.; Guetzloff, T.F.; Rice, J.A. (1997). Fractionation of pesticide residues bound to humin. Soil Sci., 162, 421-429.

Yang, Z.M.; Wang, W.; Han, A.L.; Ye, Q.F.; Lu, L. (2009). Determination of herbicide ZJ0273 residue in rapeseed by radioisotopic tracing method. Food Chem., 114, 300-305.

Yang, Z.M.; Ye, Q.F.; Lu, L. (2008). Synthesis of herbicidal ZJ0273 labeled with tritium and carbon-14. J. Label. Compd. Radiopharm., 51, 182-186.

Yang, Z.M.; Ye, Q.F.; Tang, Q.H.; Lu, L. (2006). Microsynthesis of a novel herbicide, propyl 4-[2-[(4,6-dimethoxy-2-pyrimidinyl)oxy]benzylamino]benzoate. Acta Agriculturae Nucleatae Sinica, 20(5), 423-428 [in Chinese].

Ye, Q.F.; Sun, J.H.; Wu, J.M. (2003). Causes of phytotoxicity of metsulfuron-methyl bound residues in soil. Environ. Pollut., 126, 417-423.

Ye, Q.F.; Wu, J.M.; Sun, J.H. (2004). Bioavailability of bound residue derived from C-14labeled chlorsulfuron in soil and its mechanism of phytotoxicity. J. Environ. Sci., 16, 262-267.

Yukio, N.; Masahiro, M.; Kazuhiko, S., Nobuhide, W. (1996). Dimethoxypyrimidines as novel herbicides. Part 2. Synthesis and herbicidal activity of Opyrimidinylsalicylates and analogues. Pestic. Sci., 47, 115-124. 


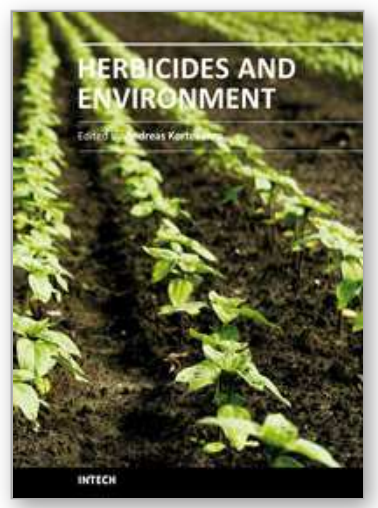

\author{
Herbicides and Environment \\ Edited by Dr Andreas Kortekamp
}

ISBN 978-953-307-476-4

Hard cover, 746 pages

Publisher InTech

Published online 08, January, 2011

Published in print edition January, 2011

Herbicides are much more than just weed killers. They may exhibit beneficial or adverse effects on other organisms. Given their toxicological, environmental but also agricultural relevance, herbicides are an interesting field of activity not only for scientists working in the field of agriculture. It seems that the investigation of herbicide-induced effects on weeds, crop plants, ecosystems, microorganisms, and higher organism requires a multidisciplinary approach. Some important aspects regarding the multisided impacts of herbicides on the living world are highlighted in this book. I am sure that the readers will find a lot of helpful information, even if they are only slightly interested in the topic.

\title{
How to reference
}

In order to correctly reference this scholarly work, feel free to copy and paste the following:

Haiyan Wang, Yanfei Zhang, Man Yu, Juying Li and Qingfu Ye (2011). Environment Behavior and Fate of a New Pyrimidynyloxybenzoic Herbicide ZJ0273 in Aerobic Soil, Herbicides and Environment, Dr Andreas Kortekamp (Ed.), ISBN: 978-953-307-476-4, InTech, Available from:

http://www.intechopen.com/books/herbicides-and-environment/environment-behavior-and-fate-of-a-newpyrimidynyloxybenzoic-herbicide-zj0273-in-aerobic-soil

\section{INTECH}

open science | open minds

\section{InTech Europe}

University Campus STeP Ri

Slavka Krautzeka 83/A

51000 Rijeka, Croatia

Phone: +385 (51) 770447

Fax: +385 (51) 686166

www.intechopen.com

\section{InTech China}

Unit 405, Office Block, Hotel Equatorial Shanghai

No.65, Yan An Road (West), Shanghai, 200040, China

中国上海市延安西路65号上海国际贵都大饭店办公楼405单元

Phone: +86-21-62489820

Fax: +86-21-62489821 
(C) 2011 The Author(s). Licensee IntechOpen. This chapter is distributed under the terms of the Creative Commons Attribution-NonCommercialShareAlike-3.0 License, which permits use, distribution and reproduction for non-commercial purposes, provided the original is properly cited and derivative works building on this content are distributed under the same license. 